of evolutionary-or, if you like, teleological-thinking so necessary to the study of biology. For in biology, because of Darwinian selection, we are entitled to ask not only "What ?" and "How ?" as in physical science, but also "Why?" and "What for?"

Because in clinical science we pride ourselves that we are building up medical knowledge we should not complacently assume that we are always doing it the right way, or making the best use of resources which in any society are bound to be limited. We should remember with John Aubrey that "Pride has been one of the greatest stoppers of the Advancement of Learning."

The defects may be only part of a temporary chapter in the history of medicine, and a symptom of a more widespread ailment. For man has put most of his efforts into improving the material state of society (and perfecting the engines of war), and has given scant attention to the ills of the mind of man and woman, and the study of their behaviour in health and disease and in society.

I know that I have spoken some heresies. If they are rather disturbing ones, my personal researches lead me to believe that the defences of the clinical scientists will be equal to them. Perhaps for another few years.
Nevertheless, with Harvey, "I fear lest I have mankind at large" (or at any rate some of my colleagues) "for my enemies, so much doth wont and custom become a second nature. Doctrine once sown strikes deep its root .... Still the die is cast and my trust is in the love of truth and the candour of cultivated minds."

\section{REFERENCES}

Chain, E. B. (1963). Nature (Lond.), 200, 441.

Clark, Sir George (1964). A History of the Royal College of Physicians of London, vol. 1. Oxford.

Jason, H. (1966). F. Amer. med. Ass., 198, 199.

Keynes, Sir Geoffrey (1958). Harveian Oration to the Royal College of Physicians. London.

- (1966). The Life of William Harvey. Oxford.

Medawar, Sir Peter (1967). The Listener, 78, 453. (12 October.) And see also The Art of the Soluble. London. 1967.

Pappworth, M. H. (1967). Human Guinea-Pigs. London.

Roth, M. (1967). Unpublished.

Rutstein, D. D. (1967). The Coming Revolution in Medicine. Cambridge, Mass

Simpson, G. G. (1963). Science, 139, 81.

Thomson, Sir Arthur (1961). Brit. med. 7., 2, 1303.

Whitteridge, G. (1964). The Anatomical Lectures of William Harvey. Edinburgh. (1966). Brit. med. 7., 2, 7.

\title{
Factors Affecting the Response to Clomiphene Therapy
}

\author{
DAVID FERRIMAN,* D.M., F.R.C.P. ; ANTHONY W. PURDIE, † M.R.C.P.GLASG., F.R.C.S.GLASG., F.R.C.O.G. \\ MICHAEL CORNS, $\ddagger$ M.SC
}

Brit. med. F., 1967, 4, 444-446

It has been well established that clomiphene citrate (Clomid), a compound allied to chlorotrianisene (Tace), is capable of inducing ovulation in a substantial proportion of patients suffering from anovulatory infertility, with consequent relief of infertility in a significant number. In the present study we attempt to determine factors concerned with the outcome of such therapy.

\section{Material and Methods}

Fifty-five patients attending one gynaecological and one endocrine clinic with amenorrhoea, severe oligomenorrhoea, or mild oligomenorrhoea with anovulatory cycles have been treated with clomiphene. Forty-one of them were also suffering from infertility or amenorrhoea of more than two years' duration. All the patients had a full medical and gynaecological examination to exclude medical or gross gynaecological disorders likely to be associated with menstrual disturbance or infertility. All kept a basal temperature chart for at least six months, often much longer, before treatment, and continued to do this throughout therapy. Gynaecography was performed in 51 . In those with infertility endometrial curettage and culture for Mycobacterium tuberculosis, hysterosalpingography, and analysis of the husbands' seminal fluid was carried out. Follicle-stimulating hormone assays were not done, but primary ovarian disorder is thought to have been unlikely on clinical grounds.

Oestrogen excretion assays were carried out on 39 patients, both under basal conditions and after treatment with clomiphene. At first, assays were done at weekly intervals for one

- Physician, North Middlesex Hospital, London N.18. † Senior Obstetrician and Gynaecologist, North Middlesex Hospital, London N.18.

‡ Steroid Chemist, North Middlesex Hospital, London N.18. month after the start of treatment; experience showed that oestrogen responses tended to be maximal between the second and third weeks, and in the later stages of the investigations assays were performed only on specimens obtained during this period. Total oestrogen assays were made with a modified form of Ittrich's method (Corns and James, 1967), which had a nonspecific fluorescent background of $10 \mu \mathrm{g}$. $/ 24$ hours.

Various dosage schedules have been used, ranging from 50 mg. b.d. for five days to $100 \mathrm{mg}$. b.d. for two weeks. No obvious advantages were found for the longer schedules, and eventually a standard dosage of $100 \mathrm{mg}$. b.d. for five days was used. All patients were given at least three courses of treatment before it was concluded that no benefit was to be obtained.

\section{Results}

Criteria Used in Evaluation of Results.-Three types of response to clomiphene were distinguished: (1) no response, (2) menstruation without ovulation (as evidenced by absence of progestational temperature rises), and (3) ovulation and menstruation. Examination of our data suggested that the most meaningful classification would be into those with and those without evidence of ovulation. The criterion used for the diagnosis of polycystic ovaries was a gynaecography index exceeding 21 (Ferriman and Purdie, 1965).

Ovulatory Response in Relation to Duration of Cycles.Consideration of our findings suggested that a significant division would be into patients with menstrual cycles less than or exceeding six months. The data have been analysed accordingly and the results are shown in Table I. Clearly patients with cycles of less than six months' duration fared better than those with cycles exceeding this figure. The difference is highly significant at the $0.1 \%$ level $\left(x^{2}=12.40\right)$. 
TABLB 1.-Relation of Ovulatory Response to Duration of Cycles

\begin{tabular}{c|c|c}
\hline \multirow{2}{*}{ Cycles } & \multicolumn{2}{|c}{ Patients } \\
\cline { 2 - 3 } & Ovulated & Total \\
\hline$<6$ months & 14 & 29 \\
& 24 & 26 \\
\hline
\end{tabular}

Ovulatory Response in Relation to Basal Oestrogen Excretion. -The Chart relates basal oestrogen excretion for each patient to the increments of oestrogen excretion after clomiphene therapy and the presence or absence of an ovulatory response. Scrutiny suggests significant dividing lines between basal oestrogen excretions above or below $21 \mu \mathrm{g} . / 24$ hours, and between increments of oestrogen excretion above and below $40 \mu \mathrm{g} . / 24$ hours. Patients with basal excretions below $21 \mu \mathrm{g} . / 24$ hours generally have increments of excretion below $40 \mu \mathrm{g} . / 24$ hours and lack of ovulatory response. Patients with basal oestrogen excretions above $21 \mu \mathrm{g} . / 24$ hours generally have increments of excretion above $40 \mu \mathrm{g} . / 24$ hours and an ovulatory response. Several patients show high increments of excretion without ovulation, though usually with menstruation. Others show ovulation with low increments of excretion; examination of basal temperature charts showed that this was invariably caused by failure to collect specimens for assay during the progestational phase, a defect in our experimental design. The data are set out in Table II. The tendency for ovulatory response to be related to higher basal oestrogen excretion is clear, and the figures approach significance at the $5 \%$ level $\left(\chi^{2}=3.582\right.$ by Yates's method ; Maxwell, 1961).

Ovulatory Response in Relation to Ovarian Size.-Table III shows ovulatory response in patients with normal and polycystic ovaries. It is clear that patients with polycystic ovaries

TABLB II.-Relation of Ovulatory Response to Basal Oestrogen Excretion

\begin{tabular}{c|c|c}
\hline \multirow{2}{*}{ Oestrogen Excretion } & \multicolumn{2}{|c}{ Patients } \\
\cline { 2 - 3 }$<21 \mu \mathrm{g} . / 24$ hours & Ovulated & Total \\
\hline$>21$ & 4 & 11 \\
\hline
\end{tabular}

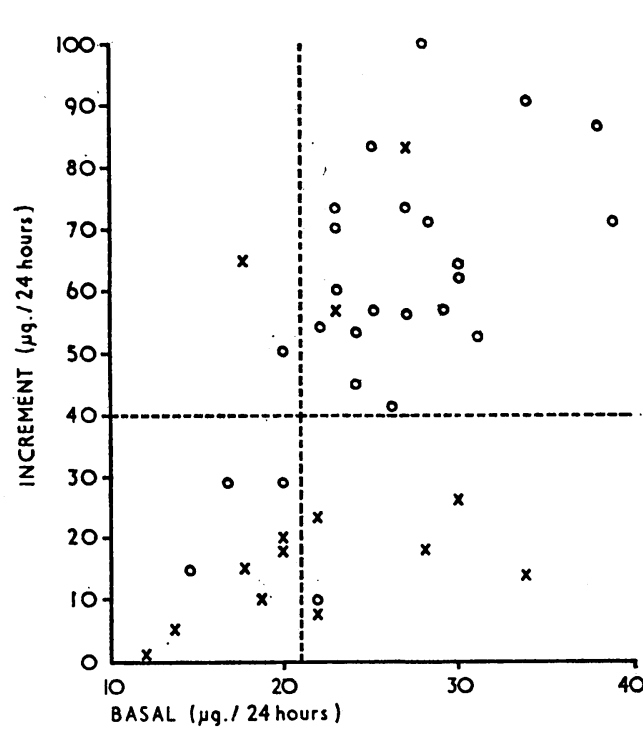

Relation of basal oestrogen excretion to incremen of oestrogen excretion and ovulatory response after clomiphene therapy. $\mathrm{O}=$ Patients with ovulatory

response. $\mathrm{X}=$ Those showing lack of response.

TABLB III.-Relation of Ovulatory Response to Ovarian Sixe

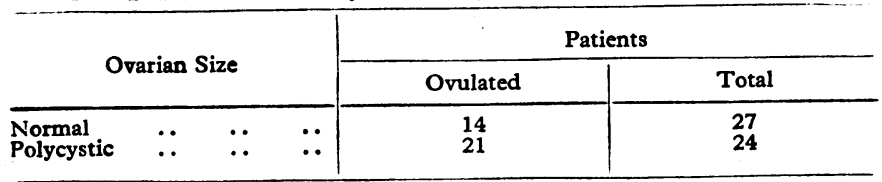

fare better than those with normal ovaries. The difference is very significant at the $1 \%$ level $\left(\chi^{2}=7.498\right)$.

Ovulatory Response in Relation to Duration of Cycles and Orarian Size.-The data relating ovulatory response to duration of cycles have been broken down into groups with normal and polycystic ovaries in Table IV. The same tendency for patients with cycles of less than six months' duration to fare better than those with longer cycles is shown in both groups, though this is much more pronounced in patients with normalsized ovaries than in those with polycystic ovaries. Patients with polycystic ovaries noticeably predominated in the group with cycles of less than six months' duration, and those with normal-sized ovaries noticeably predominated in the group with longer cycles; this is very significant at the $1 \%$ level $\left(\chi^{2}=10.283\right)$.

TABLB IV - Comparison of Ovulatory Responses in Relation to Duration of Cycles Between Patients with Normal and Polycystic Ovaries

\begin{tabular}{|c|c|c|c|c|}
\hline \multirow{3}{*}{ Cycles } & \multicolumn{4}{|c|}{ Ovaries } \\
\hline & \multicolumn{2}{|c|}{ Normal } & \multicolumn{2}{|c|}{ Polycystic } \\
\hline & Ovulated & Total & Ovulated & Total \\
\hline $\begin{array}{l}>6 \text { months } \\
<6 \quad \text { " }\end{array}$ & $\begin{array}{l}8 \\
6\end{array}$ & $\begin{array}{r}20 \\
7\end{array}$ & $\begin{array}{r}5 \\
16\end{array}$ & $\begin{array}{r}7 \\
17\end{array}$ \\
\hline
\end{tabular}

Conception.-Nine out of the 41 patients complaining of infertility conceived. Five have successfuly gone to term and three were still pregnant at the time of writing. Pregnancy in the ninth ended in abortion. One of the patients subsequently going to term had an abortion after an earlier course of clomiphene.

Table $\mathrm{V}$ shows the incidence of conception in patients with normal and polycystic ovaries. Clearly, patients with normal ovaries fared better than those with polycystic ovaries. The figures approach significance at the $5 \%$ level $\left(\chi^{2}=3.197\right.$ by Yates's method; Maxwell, 1961).

TABLB V.-Relation of Conception to Ovarian Size

\begin{tabular}{lll|c|c|c}
\hline \multicolumn{3}{c}{ Ovarian Size } & & \multicolumn{3}{c}{ Patients } \\
\cline { 3 - 5 } & & & Conceived & Total \\
\hline Normal & $\ldots$ & $\ldots$ & $\cdots$ & 6 & 16 \\
\hline
\end{tabular}

\section{Discussion}

Our classification of response to clomiphene based upon basal temperature charts and the occurrence or otherwise of menstruation complement the findings of Bell and Loraine (1966), based on steroid excretion studies. These workers found three types of response: (1) no change in oestrogen nor in pregnanediol excretion; (2) a rise in oestrogen but none in pregnanediol excretion; and (3) a rise in both oestrogen and pregnanediol excretion similar to that found in the normal menstrual cycle.

Our finding that patients with basal oestrogen excretion levels exceeding $21 \mu \mathrm{g} . / 24$ hours respond better than those with lower excretion levels is very similar to findings reported by Bell and Loraine (1966) and Townsend et al. (1966), bearing in mind the nonspecific background fluorescence of $10 \mu \mathrm{g} . / 24$ hours found in our method.

Our group of patients with menstrual cycles of less than six months' duration contain a marked preponderance with polycystic ovaries, while the group with cycles of more than six months' duration contain a marked preponderance of normalsized ovaries. The explanation in the present state of knowledge can only be conjectural. If one postulates an underlying disturbance of hypothalamic centres governing gonadotrophin production, the milder forms of the disorder may have some 
residual follicle stimulating hormone secretion leading to the production of polycystic ovaries (Ferriman, 1960); all follicle stimulating hormone secretion may have disappeared in the more severely affected patients. The development of sensitive and precise radio-immunological assays for gonadotrophins may shed some light on the problem before long.

The incidence of conception in our series ( 9 out of 41) is higher than we would have anticipated from our previous experiences in the field. This has been the experience of many other workers (Greenblatt, 1966). It is not possible to make a precise statistical assessment of the comparative value of this drug in the absence of control data. The provision of such data would be of great interest.

It is odd that while patients with polycystic ovaries show a better ovulatory response to clomiphene than those with normalsized ovaries their conception rate should be lower. Perhaps the thickened capsules of the polycystic ovaries interfere with the release of ova, or the increased production of androgen by these ovaries impairs nidation.

\section{Summary}

The ovulatory response to clomiphene is significantly better in patients with menstrual cycles of less than six months' duration compared with those whose cycles exceed this figure, and in patients with polycystic ovaries compared with those whose ovaries are of normal size. It is better in patients with basal oestrogen excretions exceeding $21 \mu \mathrm{g} . / 24$ hours than in those whose excretion levels fall below this figure (obtained by a method having a nonspecific background fluorescence of 10 $\mu g . / 24$ hours), though the difference does not quite reach formal significance.

Patients with normal-sized ovaries conceive more readily than those with polycystic ovaries. The difference does not quite reach formal significance.

We wish to thank Dr. D. Mansell-Jones and Dr. J. P. Birkett, of Merrell-National, for supplies of Clomid and for a generous grant towards expenses; Dr. W. G. Dangerfield for laboratory facilities; Mrs. F. Norris for statistical analyses; and Miss S. Ferriman and Miss E. Whiteley for preparation of the diagram.

\section{REFERENCES}

Bell, E. T., and Loraine, J. A. (1966). Lancet, 1, 626. Corns, M., and James, V. H. T. (1967). In preparation. Ferriman, D. (1960). Postgrad. med. F., 36, 186. and Purdie, A W. (1965). Brit. med. 269. Greenblatt, R. B. (1966). Ovulation, p. 134. Philadelphia. Maxwell, A. E. (1961). Analysing Qualitative Data, p. 20. London. Maxwell, A. E. (1961). Analysing Qualitative Data, p. 20. London. Townsend, S. L., Brown, J. B., Johnstone, J. W., Adey, F. D., Evans, J. H., and Taft, H. P. (1966). F. Obstet. Gynaec. Brit. Cwlth, 73,

\title{
Current Concepts in the Treatment of Anovulation
}

\author{
E. RABAU,* M.D.; D. M. SERR,* M.B.; S. MASHIACH,* M.D.; V. INSLER,* M.B., B.CH. \\ M. SALOMY,* M.D.; B. LUNENFELD, $\dagger$ M.D.
}

Brit. med. F., 1967, 4, 446-449

When mechanical or anatomical lesions are excluded, disturbances of ovulation and corpus luteum function represent the main cause of infertility.

The factors which disturb the proper function of the reproductive system from within may stem from any of the participating cells or populations of cells in the central nervous system, the pituitary gland, the ovary, or perhaps even the uterus. These factors may involve faulty stimulation (abnormal magnitude, sequence of appearance, or time of action of stimuli) or faulty response of the target cells or organs. Each and every one of these factors, if sufficiently powerful, or when acting long enough, may lead to an imbalance of the hormonal feedback mechanism and consequently to impaired fertility. In the majority of cases some absolute or relative primary or secondary abnormality in the nature or magnitude of gonadotropic stimulus exists, regardless of the primary cause. A convenient simplification is to divide these patients into two groups: those with gonadotropic insufficiency due to primary failure in production of gonadotropins, and those with abnormal gonadotropic stimulus due to disturbed release of gonadotropic hormones.

- Department of Obstetrics and Gynaecology, Tel-Hashomer Government Hospital and Tel Aviv University Medical School, Tel Aviv, Israel.

† Institute of Endocrinology, Tel-Hashomer Government Hospital and Tel Aviv University Medical School, Tel Aviv, Israel.
Preparations of human gonadotropins and clomiphene citrate have proved to be of definite value in the treatment of these two groups of patients.

Recently gonadotropic extracts from human post-mortem pituitaries and human menopausal urine have been made available for clinical use. These preparations in conjunction with human chorionic gonadotropins have proved capable of inducing ovulation. Numerous pregnancies have resulted from such treatment (Gemzell, 1966 ; Lunenfeld and Donini, 1966 ; Shearmán, 1966 ; Rabau et al., 1967). It was shown by Crooke et al. (1963) and Diczfalusy et al. (1964) that gonadotropic preparations derived either from human post-mortem pituitary glands or from postmenopausal urine, administered to the same patients, provoked a similar response as judged by steroid excretion patterns and by vaginal or endometrial morphology.

Another approach to the treatment of anovulation was made possible by the introduction of clomiphene citrate (MER-41). This synthetic non-steroid preparation is a derivative of chlorotrianisene (TACE) and possesses both oestrogenic and anti-oestrogenic properties (Greenblatt, 1966). The exact mechanism of action of clomiphene in inducing ovulation is as yet unclear. Since urinary excretion of gonadotropins was reported to be increased during or immediately after administration of clomiphene (Dickey et al., 1965), it has been suggested that the drug acts either directly or indirectly on 